\title{
0 debate sobre a maioridade penal
}

Jorge Wohney Ferreira Amaro ${ }^{1}$

\section{Resumo}

A maioridade penal é tema de controvérsias no momento atual de nossa sociedade. Este artigo faz uma súmula do Estatuto da Criança e do Adolescente (ECA), bem como do Código Penal atual frente a este problema. $\mathrm{O}$ autor, após abordar o vértice psiquiátrico, propõe a extinção do artigo 121 do ECA, bem como outras medidas substitutivas.

Segundo o Código Penal, a Constituição, a Lei de Segurança Nacional e o Estatuto da Criança e do Adolescente (ECA), menores de 18 anos são penalmente inimputáveis. A lei de $\mathrm{n}^{0} 8.069$, de 13 de julho de 1990, dispõe sobre o Estatuto da Criança e do Adolescente e dá outras providências.

O ECA considera, através de alguns de seus artigos, o seguinte:

Das disposições preliminares

Art. $1^{\circ}$ : Esta lei dispõe sobre a proteção integral à criança e ao adolescente.

Art. $2^{\circ}$ : Considera-se criança, para os efeitos desta lei, a pessoa até 12 anos de idade incompletos, e adolescente aquela entre doze e dezoito anos de idade.

Das entidades de atendimento; Seção I; Disposições gerais:

Art. 90: As entidades de atendimento são responsáveis pela manutenção das próprias unidades, assim como pelo planejamento e execução de programas de proteção e socioeducativos destinados a crianças e adolescentes em regime de:

I - orientação e apoio sociofamiliar;

II - apoio socioeducativo em meio aberto;

III - colocação familiar;

IV - abrigo;

$\mathrm{V}$ - liberdade assistida;

VI - semiliberdade;

VII - internação.

Da prática de ato infracional; Capítulo I; Dos direitos individuais:

Art. 106: Nenhum adolescente (maior de 12 e menor de 18 anos) será privado de sua liberdade, senão em flagrante de ato infracional ou por ordem escrita e fundamentada da autoridade judiciária competente.

Das medidas socioeducativas; Disposições gerais:

Art. 112: Verificada a prática infracional, a autoridade competente poderá aplicar ao adolescente as seguintes medidas:

I - advertência; 
II - obrigação de reparar o dano;

III - prestação de serviço à comunidade;

IV - liberdade assistida;

V - inserção em regime de semiliberdade;

VI - internação em estabelecimento educacional;

VII - qualquer uma das previstas no artigo 101, I a VI, ou seja: 101 - I - encaminhamento aos pais ou responsáveis mediante termo de responsabilidade; 101 - II - orientação, apoio e encaminhamento temporários; 101 - III - matrícula e freqüência obrigatória em estabelecimento oficial de ensino fundamental; 101 IV - inclusão em programa comunitário ou oficial de auxílio à família, à criança a ao adolescente; 101 - V requisição de tratamento médico, em regime hospitalar ou ambulatorial; 101 - VI - inclusão em programa oficial ou comunitário de auxílio, orientação e tratamento a alcoólatras e toxicômanos.

Seção VII; Da internação:

Art. 121; parágrafo 3: Em nenhuma hipótese, o período máximo de internação excederá a três anos.

No parágrafo $4^{\circ}$ : Atingido o limite estabelecido no parágrafo anterior, o adolescente deverá ser liberado, colocado em regime de semiliberdade ou de liberdade assistida.

Art. 122: A medida de internação só poderá ser aplicada quando a infração for cometida mediante grave ameaça ou violência, o infrator for reincidente, ou por descumprimento de medida anterior.

A idade mínima para maioridade penal estabelecida em 18 anos de idade, prevista pelo ECA, é estabelecida conforme orientação da ONU.

Com o assassinato dos namorados Liana Friedenbach, 16, e Felipe Silva Caffé, 19, em EmbuGuaçu (Grande São Paulo), num crime liderado por um menor de 16 anos, segundo a versão da polícia, reacendeu-se o debate no País sobre a redução da maioridade penal. Vários setores da coletividade manifestaram-se, como os ligados ao Judiciário, à Igreja etc. A psiquiatria não poderia furtar-se de opinar sobre essa questão.

Os vértices segundo o qual o tema pode ser focalizado são multidisciplinares, englobando, entre outros, os vértices sociológico, jurídico, teológico, psicológico, psiquiátrico etc.

Os debates estão ocorrendo por meio dos instrumentos de comunicação e apontam divergências que, em resumo, são: 1) diminuição da maioridade penal; 2) permanência da maioridade penal segundo o Código Penal atual; 3) permanência da maioridade penal, porém com oficialização clara e descrita no ECA da permanência prolongada que ultrapasse, de longe, os três anos nos casos de crimes hediondos, ou seja, a retirada do artigo 121 do ECA; 4) Qualquer idade seria imputável.

Sob o vértice jurídico, temos que apontar como a legislação atual concebe o tratamento dos delitos cometidos por menores de 18 anos e tecer algumas considerações sobre conceitos e ideologias subjacentes.
No capítulo da imputabilidade penal, o Código Penal assim concebe como inimputáveis:

Artigo 26: É isento de pena o agente que, por doença mental ou desenvolvimento mental incompleto ou retardado, era, ao tempo da ação ou da omissão, inteiramente incapaz de entender o caráter ilícito do fato ou de determinar-se de acordo com esse entendimento.

Artigo 27: Os menores de 18 anos são penalmente inimputáveis, ficando sujeitos às normas estabelecidas na legislação especial (Oliveira e cols., 2001).

Algumas noções jurídicas importantes devemos lembrar para podermos entender pontos de vista (De Jesus, 2001). A imprudência é a prática de um fato perigoso. A negligência é a ausência de precaução ou indiferença frente ao ato realizado. A imperícia é a falta de aptidão para o exercício de arte ou profissão.

Existe uma situação jurídica concebida como culpa inconsciente. Nela, o resultado não é previsto pelo agente, embora previsível. É a culpa que se manifesta pela imprudência, negligência ou imperícia.

A imputabilidade penal é o conjunto de condições pessoais que dão ao agente capacidade para lhe ser juridicamente imputada a prática de um fato punível. Imputável é o sujeito mentalmente são e desenvolvido, capaz de entender o caráter ilícito do fato e de se determinar de acordo com esse entendimento. A imputabilidade pode ser excluída por determinadas causas, denominadas causas de inimputabilidade.

A menoridade penal também constitui causa de exclusão da imputabilidade, encontrando-se abrangida pela expressão "desenvolvimento mental incompleto" (artigo 26).

A inimputabilidade também se aplica às doenças mentais ou de desenvolvimento ou retardado.

Entende-se, pelo Código Penal, desenvolvimento mental incompleto como aquele que ainda não se concluiu, como os casos dos menores de dezoito anos e os silvícolas inadaptados.

Entende-se desenvolvimento mental retardado os oligofrênicos (idiotas, imbecis e débeis mentais) e surdos-mudos.

Damásio de Jesus, em sua obra Código Penal Anotado, lembra a figura jurídica do conceito de semi-responsabilidade. Assim, entre a imputabilidade e a inimputabilidade, existe um estado intermediário com reflexos na culpabilidade e, por conseqüência, na responsabilidade do agente. Cita, por exemplo, as formas menos graves de debilidade mental, os estados incipientes, estacionários ou residuais de certas psicoses e também as chamadas personalidades psicopáticas (p.p. 123). O agente responde pelo crime com pena privativa de liberdade atenuada ou medida de segurança.

Pena é a sanção aflitiva imposta pelo Estado, mediante ação penal, ao autor de uma infração (penal) como retribuição de seu ato ilícito, consistente 
na diminuição de um bem jurídico, e cujo fim é evitar novos delitos.

Sob o vértice psiquiátrico e psicológico, temos que distinguir jovens comprovadamente portadores de distúrbios psiquiátricos de jovens com distúrbios graves no desenvolvimento da personalidade e também de jovens sem distúrbios psiquiátricos e sem distúrbios graves no desenvolvimento da personalidade. A pergunta que deve ser feita é se o jovem está consciente e tem condições de compreender o seu ato criminoso. Quando a cognição não está afetada por um delírio, por alucinações ou por confusão mental, o adolescente sabe que aquele ato é criminoso e que poderá ser punido; portanto, é consciente e conhecedor de seu ato. Por outro lado, jovens com transtornos de personalidade anti-social com um padrão de desconsideração e violação dos direitos dos outros não irão, em apenas três anos, recuperar-se dessa estrutura básica. É evidente que os jovens com distúrbios psiquiátricos requerem um tratamento psiquiátrico, enquanto que os jovens com distúrbios de personalidade anti-social requerem um tratamento socioterápico de longa duração em meio apropriado.

Há 40 anos pratico a psicanálise, tratando e pesquisando estruturas mentais em pessoas lúcidas que poderiam psiquiátrica e socialmente ser consideradas normais. Constatamos que, para mudar padrões de conduta, de valores e levar o indivíduo a poder administrar seus instintos agressivos e libidinosos, bem como se conscientizar de sua capacidade de construir e destruir relações, pode-se levar mais de uma década nos casos de sucesso terapêutico. Nessas condições, os três anos de internação de menores com delitos graves são insuficientes para mudanças.

É opinião fundamentada pela psiquiatria, por meio do DSM-IV, que um transtorno de personalidade é um padrão persistente e não temporário de vivência íntima ou comportamento que se desvia acentuada- mente das expectativas da cultura do indivíduo, é invasivo e inflexível, tendo seu início na adolescência, é estável ao longo do tempo e provoca sofrimento ou prejuízo. Existem diferentes formas de expressão de transtornos de personalidade descritos no DSM-IV, porém são os Transtornos da PersonalidadeAnti-Social (TPAS) (301.7) que nos interessa focalizar. Os portadores de TPAS apresentam-se com um padrão de desrespeito e violação dos direitos dos outros, que se inicia na infância ou começo da adolescência e continua na idade adulta. Esse padrão é também conhecido como sociopatia, psicopatia. Enquanto portadores de distúrbios psiquiátricos podem beneficiar-se de medicações, os sociopatas são refratários a medicação e lúcidos de seus atos.

Podemos inferir por meio desses dados que deverá haver uma distinção entre os diferentes grupos de jovens e de seus diagnósticos.

A diminuição da maioridade penal pura e simplesmente não resolveria o problema prático. Algumas conclusões podem ser colocadas: a eliminação do artigo 121 do ECA e o aumento do número de anos em que o menor ficará privado de sua liberdade, dependendo da gravidade do crime, enquanto sua periculosidade para o meio ambiente permanecer, e a adoção de medidas profiláticas no meio social para diminuir o número de jovens que surgem com atividade anti-social; a formação de uma junta profissional especializada (psiquiatras, psicólogos, psicanalistas, assistentes sociais etc.), cuja responsabilidade é aferir se a variável periculosidade anti-social permanece, para opinar sobre a possível liberação da internação nos estabelecimentos especializados, e não apenas um número três, quatro, cinco ou dez anos, que não são capazes de controlar a variável periculosidade anti-social.

A meu ver, sob o conceito de imprudência, negligência e imperícia, abordados neste artigo, o Estado seria passível de ser acusado por permitir a existência do artigo 121 do ECA.

\section{Referências bibliográficas}

De Jesus, D.E. - Código Penal Anotado. 11ª edição, São Paulo, Saraiva, 2001.

Oliveira, J. et al. - Código Penal, $16^{a}$ edição, São Paulo, Saraiva, 2001. 